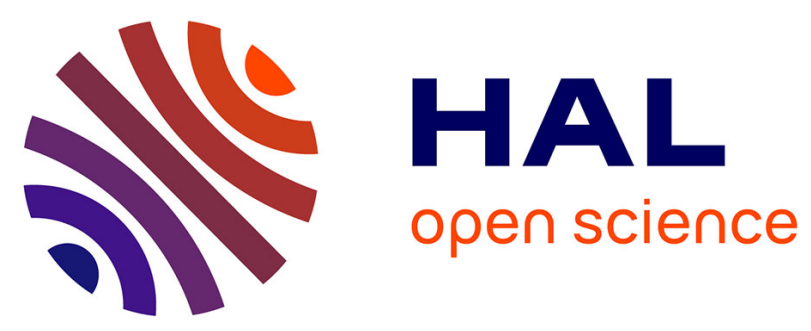

\title{
On the time-temperature equivalency in green wood: Characterisation of viscoelastic properties in longitudinal direction
}

\author{
Jana Dlouha, Bruno Clair, Olivier Arnould, Petr Horacek, Joseph Gril
}

\section{- To cite this version:}

Jana Dlouha, Bruno Clair, Olivier Arnould, Petr Horacek, Joseph Gril. On the time-temperature equivalency in green wood: Characterisation of viscoelastic properties in longitudinal direction: Characterisation of viscoelastic properties in longitudinal direction. Holzforschung, 2009, 63 (3), pp.327333. 10.1515/HF.2009.059 . hal-00437887

\section{HAL Id: hal-00437887 \\ https://hal.science/hal-00437887}

Submitted on 17 Jan 2019

HAL is a multi-disciplinary open access archive for the deposit and dissemination of scientific research documents, whether they are published or not. The documents may come from teaching and research institutions in France or abroad, or from public or private research centers.
L'archive ouverte pluridisciplinaire HAL, est destinée au dépôt et à la diffusion de documents scientifiques de niveau recherche, publiés ou non, émanant des établissements d'enseignement et de recherche français ou étrangers, des laboratoires publics ou privés. 


\section{On the time-temperature equivalency in green wood: Characterisation of viscoelastic properties in longitudinal direction}

\author{
Jana Dlouhá1,2,*, Bruno Clair', Olivier Arnould1, \\ Petr Horáček² and Joseph Gril'1 \\ ${ }^{1}$ Laboratoire de Mécanique et Génie Civil (LMGC), \\ Université Montpellier 2, CNRS UMR-5508, \\ Montpellier, France \\ ${ }^{2}$ Mendel University of Agriculture and Forestry in Brno \\ (MZLU in Brno), Department of Wood Science, Brno, \\ Czech Republic \\ ${ }^{*}$ Corresponding author. \\ Laboratoire de Mécanique et Génie Civil (LMGC), Université \\ Montpellier 2, CNRS UMR-5508, cc 048 - Place Eugène \\ Bataillon, 34095 Montpellier Cedex 5, France \\ Tel.: +33467149344 \\ Fax: +33467144792 \\ E-mail: dlouha@Imgc.univ-montp2.fr; yanadlo@seznam.cz
}

\begin{abstract}
Aiming at modelling tree mechanics, viscoelastic properties of green wood along fibres was investigated through a sequence of creep tests in the temperature range of $30^{\circ} \mathrm{C}-70^{\circ} \mathrm{C}$. The apparent validity of time-temperature equivalency was questioned by discrepancies evidenced in the approximated complex plane (ACP). This paradox was solved by assuming that the temperature not only accelerates the viscoelastic processes but also slightly increases their intensity. This softening effect of the temperature on the compliance was described by a 2nd degree polynomial. Time-temperature dependency fitted very well to the Arrhenius law up to $60^{\circ} \mathrm{C}$. Based on the ACP, the power law was proposed for modelling creep behaviour in green wood. The method was successfully used for all specimens investigated.
\end{abstract}

Keywords: green wood; time-temperature equivalency; viscoelastic properties.

\section{Introduction}

In mechanical analysis of stress accumulation and shape regulation in growing trees, the viscoelastic nature of wood tissues is often neglected (Wilson and Archer 1979; Fournier et al. 1994). Rheological parameters are not taken into consideration for viscoelastic calculations (Gril and Fournier 1993), partly because experimental data are not available. Therefore, a significant bias may be introduced in long-term predictions. Previous works on the rheology of green wood, i.e., wood that was never dried under the fibre saturation point, focused on the behaviour of wood across the grain (Bardet 2001; Placet et al. 2007), which is of little relevance for modelling of tree mechanics where properties along the fibres are predominant.

For long-term predictions, accelerated experimental methods have to be used. One of them, used for static testing, is based on time-temperature equivalency stating that increasing the temperature is equivalent to stretching the real-time of the creep response. Based on a sequence of short-term creep tests performed at increasing temperature levels, corresponding compliance curves are shifted along the log time axis to generate a creep master curve characteristic of long-term behaviour of a given material.

Viscous properties of wood are determined based on the behaviour of the amorphous matrix made up of lignin and a variety of hemicelluloses. In the water-saturated state, such as under green conditions, hemicelluloses are already "soft" at room temperature. Thus, further softening of wood tissues, which occurs for quasi-static loading or at low frequencies nearby $70^{\circ} \mathrm{C}$, was ascribed to the glass transition of lignin (Kelley et al. 1987). Thermal activation of secondary relaxations occurring below the glass transition temperature is usually described by Arrhenius law, where the characteristic time $\tau$ of the viscoelastic process is related to the absolute temperature $T$ through an apparent activation energy $W$.

Salmén (1984) reported the applicability of the timetemperature equivalency in wood for temperatures above the glass transition of lignin. This author has also confirmed the validity of the Arrhenius law. Many other authors predicted the long-term behaviour of wood in the hygroscopic region based on this concept (Le Govic et al. 1987; Genevaux 1989). However, these considerations relied mostly on visual assessment of the smoothness of the master curve. While investigating the experimental data in the Cole-Cole plot (McCrum et al. 1967), Bardet (2001) reported on some discrepancy of the time-temperature equivalency as described by the Arrhenius law. Placet et al. (2007) found that time-temperature equivalency could not be applied to the whole viscoelastic range but seems to be valid within each transition state.

In amorphous polymers, such as rubber, an effect of temperature on stress of pre-deformed specimen, usually called entropic (or rubber) elasticity, has been demonstrated. This effect can be accounted for multiplying the compliance by a correction factor proportional to the temperature. In particular in regions where the viscoelastic function is flat, the need of this factor is more important to obtain satisfactory matching of creep curves (Ferry 1980). In the case of wood, the applicability of such a correction is not straightforward because of its complex structure (Salmén 1984). 
The aim of the present work was to check the validity of the above-mentioned principles for wood and identify a generic rheological model applicable to wood specimens of different species, densities, nature and anatomical feature. According to the considered applications for tree mechanics, the focus was on viscoelastic properties of green wood along the fibres. With this goal in mind, tensile creep tests in longitudinal direction were performed in the temperature range of $30^{\circ} \mathrm{C}-70^{\circ} \mathrm{C}$.

\section{Material and methods}

\section{Wood material and creep equipment}

Wood of five tropical species (see Table 1) was selected for their contrasted density and anatomical features. Tensile specimens were cut along the fibre direction $\left(100 \times 6 \times 2 \mathrm{~mm}^{3}\right.$; L, T, R). Both ends were provided by heads glued on the specimen with MDI glue for green wood. Sphere-groove like joints were used to ensure pure axial loading and additional clamps to improve the transmission of axial loads between the heads and the core of the specimen (see Figure 1). Altogether, 12 specimens were tested.

Isotherm creep tests were carried out on a tensile test device (Hunt and Darlington 1978) modified for testing green wood by immersing the specimen in a water bath accurately controlled in temperature $\left( \pm 0.1^{\circ} \mathrm{C}\right)$. Considering thermal expansion ratio of $-7.10^{-6}{ }^{\circ} \mathrm{C}^{-1}$ in the tangential direction evaluated for green wood from a previous study (Gril et al. 1993), thermal dilation may induce the underestimation of the compliance by approximately $0.04 \%$, which is negligible compared to effects discussed later. The deformation along the grain was measured by a pair of strain gages. Three-wire gages were used to avoid changes in the lead wire electrical resistance with fluctuations of the room and bath temperature. Moreover, silicon coating was applied to limit disturbances of the gage output due to water currents and reduce the risk of gage detachment. During storage, sample preparation and testing, specimens were kept in wet conditions and if possible at low temperature.

\section{Experimental procedure}

Each specimen was submitted to stabilisation-creep-recovery cycles performed at isotherms between $30^{\circ} \mathrm{C}$ and $60^{\circ} \mathrm{C}$, as illus-

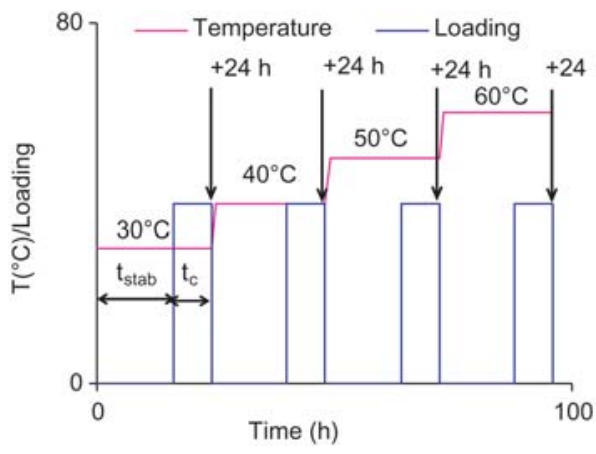

Figure 2 Applied cycling schedule. $t_{\text {stab }}$ : stabilisation time; $t_{c}$ : creep time.

trated in Figure 2. Prior to the loading, the specimen was stabilised during $15 \mathrm{~h}$ at a corresponding temperature. Afterwards, a constant load was applied during $8 \mathrm{~h}$, followed by a short recovery period and heating to the following temperature taking together approximately $1 \mathrm{~h}$. Thus, one isotherm took $24 \mathrm{~h}$ and the whole procedure hold in 1 week. Preliminary tests showed that a temperature step of $10^{\circ} \mathrm{C}$ gives an optimal overlapping of creep curve in the ACP plot.

Loading taking approximately $2 \mathrm{~s}$, the point corresponding to the half-load was considered as a starting point of each test $\left(t_{c}=0\right)$ (Figure 3a). Experimental values corresponding to $t_{c}<4 \mathrm{~s}$ were not included in the analysis because of the dispersion of strain values due to oscillations resulting from manual loading. Then, deformation at $t_{c}=4 \mathrm{~s}$ was used to determine the instantaneous compliance $J_{i}$. Applied load corresponded to an instantaneous axial strain of approximately $500 \mu \mathrm{m} \mathrm{m}^{-1}$, far below the elastic limit (i.e., loss in linearity) generally estimated around $1.5-2 \mathrm{~mm} \mathrm{~m}^{-1}$. Frequency of data acquisition was of $10 \mathrm{~Hz}$ during the first $1000 \mathrm{~s}$ after the loading and reduced to $1 \mathrm{~Hz}$ afterwards. Data obtained by both gages were averaged and smoothed to reduce the noise effects on measurements.

\section{Data analysis}

Assuming direct applicability of time-temperature equivalency, master curves were tentatively built from experimental data using shifts along the log time axis. Then, the representation in complex plot (or Cole-Cole plot) was used for a deeper analysis of the data. This representation is generally used for dynamic

Table 1 Summary table of species used.

\begin{tabular}{llcc}
\hline Scientific name & Local name & Basic density & Elastic modulus (GPa) \\
\hline Dicorynia guyanensis Amsh. & Angélique & 0.55 & 13.18 \\
Lecythis persistens Sagot & Maho rouge & 0.65 & 19.84 \\
Licania alba (Bernoulli) Cuatrec. & Gaulette blanche & 0.85 & 27.89 \\
Oxandra asbeckii (Pulle) R.E. Fries & Mouamba & 0.85 & 26.07 \\
Virola michelii Heckel & Yayamadou montagne & 0.40 & 12.12 \\
\hline
\end{tabular}

Values of basic density and elastic modulus are issued from our measurements on a larger selection of studied species. Elastic modulus was estimated by the vibration method at $12 \%$ moisture content.

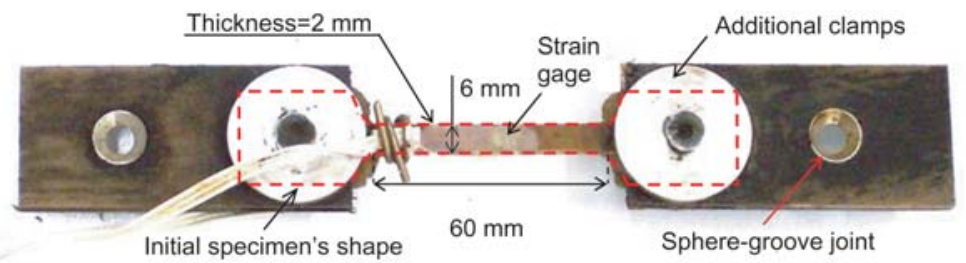

Figure 1 Geometry, clamping system and instrumentation of the tensile test specimen. 

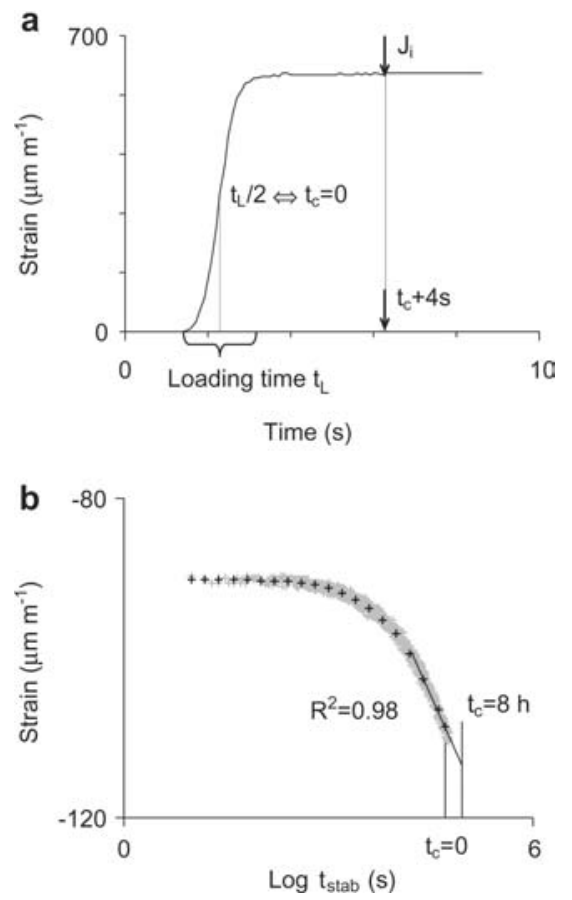

Figure 3 (a) Determination of the instantaneous compliance and of the creep test starting point. (b) Example of an extrapolation of the signal recorded during the stabilisation period into the following creep test. $t_{c}$ : creep time, $t_{\text {stab }}$ : stabilisation time, $J_{i}$ : instantaneous compliance.

tests. For static tests, an approximation of the storage $J^{\prime}$ and loss compliances $J^{\prime \prime}$ has to be applied. According to Alfrey (1948), it can be written as:

$J^{\prime} \approx J(\log t)$

$J^{\prime \prime} \approx \frac{\pi}{2} \cdot \frac{1}{\ln (10)} \frac{d J(\log t)}{d \log t}$

where $t$ is the creep time. Alfrey's approximation is valid for small $J^{\prime \prime} / J^{\prime}$ ratio and broad viscoelastic spectra, which is usually the case in wood and can be verified a posteriori on the complex plots.

This "approximated complex plane" (ACP) can be understood as a type of phase diagram giving the slope against the value, relative to the function $J(\log t)$. The assumption of time-temperature equivalency requires the alignment of individual creep curves into one continuous curve in the ACP, as this would ensure that not only the values of the $J(\log t)$ functions match, but also the slope. Moreover, rheological models applicable to wood are represented in the ACP by straight lines or circle portions so that the graphical representation of experimental data allows one to identify corresponding models (Huet 1988). Thus, ACP is a very useful tool to decide on the mathematical form of the constitutive law without any preconceived concept about the physics of the studied phenomenon.

\section{Results and discussion}

\section{Specificity of strain measurements and correction of obtained data}

Some specimens exhibited a slight initial curvature before loading, which could be attributed to gradients of maturation strain release. Bending resulting from initial straightening makes difficult interpretation of strain values measured at very first moments after the loading: a relative difference up to $60 \%$ has been observed between strains measured on both sides of the specimen at $10 \mathrm{~s}$ after loading. If attributed to the 'straightening' of the specimen, it represents an initial bowing of the order of $1 \mathrm{~mm}$. Similar problems were encountered during the measurements of the creep strain itself. In general, slight differences were observed between the measurements on both sides, but in one particular case a negative creep could be observed on one side and amplified positive creep on the other side of the specimen. This was resulting apparently from the gradient of wood properties along the specimen thickness. Hence, to obtain reliable values of developed strain, the use of two gages glued on both sides of the specimen is essential and only average values are significant.

During the stabilisation period prior to the loading cycle at a given temperature, the apparent strain is the result of different processes: recovery of preceding creep test, thermal stabilisation of the specimen (and the gages themselves), and hygrothermal recovery of locked-in strains that can occur at elevated temperatures (Gril et al. 1993). To measure the creep strain developed during the following test, the stabilisation period has to be long "enough" to neglect the strain due to other processes. Another (faster) way is to correct strains arising from these other mechanisms by extrapolating them, in log time scale, using the strain measurements during the stabilisation (Figure 3b). Note that the drift often goes in the direction opposite to the creep strain so that no correction would lead to an apparent decrease of the creep rate and thus mislead data interpretation.

\section{Building of the master curve using log time shifts}

Creep curves for each specimen were plotted as compliance versus log test time and shifted along the $x$-axis to build a master curve. Creep test performed at $T_{0}=30^{\circ} \mathrm{C}$ was taken as a reference and dimensionless shift factors, $a_{T, T O}$, were numerically adjusted. The assumption that temperature affects only the kinetics of the creep response requires that the resulting curve is smooth.

Figure 4 shows a typical example of a master curve corresponding to experimental data obtained with Oxandra asbeckii specimen (O. asbeckii 2, see below). Although the first three creep curves $\left(30^{\circ} \mathrm{C}-50^{\circ} \mathrm{C}\right)$ are quite well matched, overlapping of curves corresponding to the tests performed at higher temperatures is not complete. Nevertheless, log time shifts can be plotted against the reciprocal of temperature (Figure 5). The linear correlation between both parameters supports the applicability of time-temperature equivalency described by the Arrhenius law:

$J(t ; T)=J\left(t / a_{T ; T 0} ; T_{0}\right)$

$\log a_{T, T_{0}}=\frac{W_{0}}{\ln (10) \cdot R} \cdot\left(\frac{1}{T}-\frac{1}{T_{0}}\right)$ 


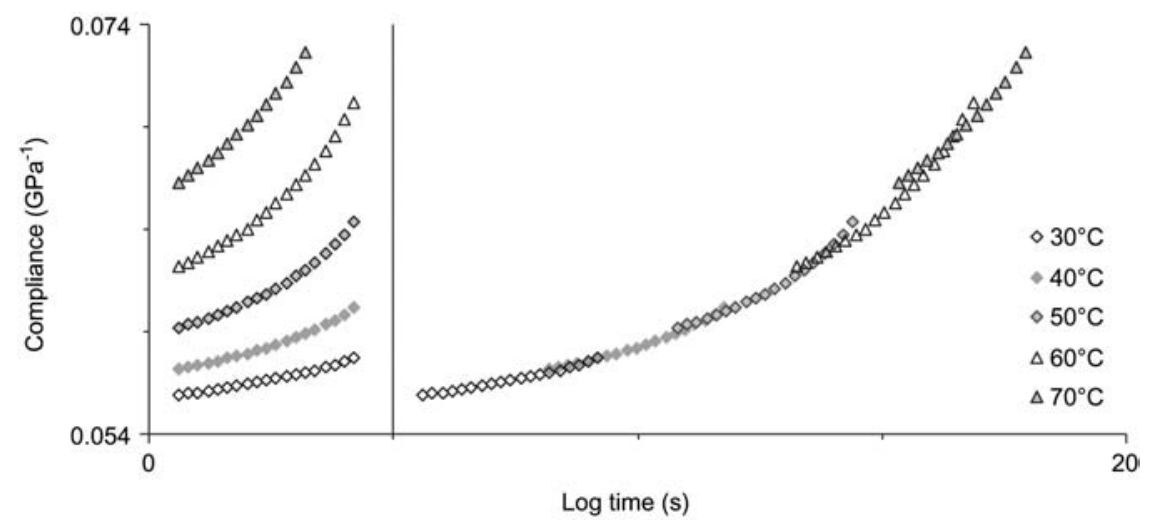

Figure 4 Master curve obtained by shifting individual creep curves for the Oxandra asbeckii 2 specimen along log time axis. Curve measured at $30^{\circ} \mathrm{C}$ is taken as a reference.

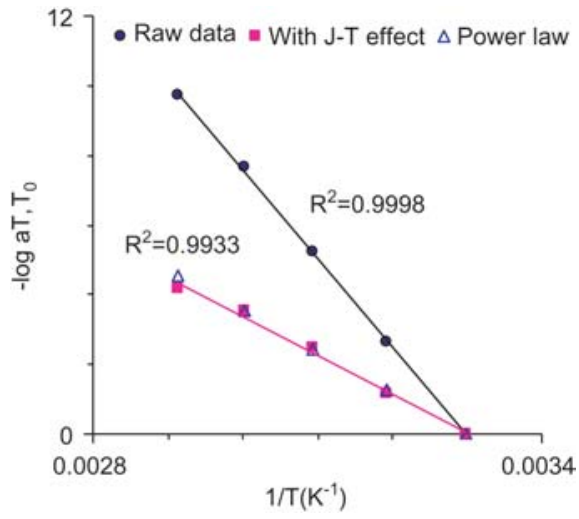

Figure 5 Temperature dependency of time shift factors issued from different optimisations and adequacy of an Arrhenius law (regression line). $J-T$ effect: experimental data corrected by the softening factor $\lambda$. Power law: adjusted values of time shifts and softening factor based on Eqs. (6-8).

where $a_{T, T O}$ is the shift factor corresponding to the stretching of the real creep time with increasing temperature, $W_{o}$ the activation energy $\left(\mathrm{J} \cdot \mathrm{mol}^{-1}\right), R$ the universal gas constant $\left(8.31 \mathrm{~J} \cdot \mathrm{mol}^{-1} \bullet \mathrm{K}^{-1}\right), T$ the temperature $(\mathrm{K})$ and $T_{0}$ the reference temperature $\left(30^{\circ} \mathrm{C}=303.15 \mathrm{~K}\right.$ in this case).
Activation energies derived from time shifts according to Eq. (4) are given in Table 2.

\section{Examination of experimental data in the complex plane}

While plotting experimental data in the ACP, discontinuities between the curves can be clearly observed (Figure 6). Individual creep curves are made up of linear segments with nearly the same slope but different $J$-intercept for each of them so that final overlapping is poor. This obviously questions the assumption that only characteristic times are affected by temperature.

Let us assume that, similar to rubber, the amorphous matrix of wood cell walls exhibits an entropic elasticity (Ferry 1980) whose effect can empirically be seen as a slight temperature dependency of the compliance $J$, denoted here as $J-T$ effect. Moreover, if we suppose that $\lambda_{(T)}$ is a multiplicative factor accounting for this effect, the equation can be written as:

$$
J(t ; T)=\lambda_{T, T_{0}} \cdot J\left(t / a_{T, T_{0}} ; T_{0}\right)
$$

Such a temperature dependency of $J$ will induce a homothetic transformation of creep curves in the ACP

Table 2 Summary table of rheological parameters assuming different hypothesis.

\begin{tabular}{|c|c|c|c|c|c|c|c|c|c|c|c|}
\hline \multirow[t]{2}{*}{ Specimen } & \multirow{2}{*}{$\begin{array}{c}W_{0} \\
\mathrm{~kJ} \cdot \mathrm{mol}^{-1}\end{array}$} & \multirow{2}{*}{$\begin{array}{c}W_{J-T+} \\
\mathrm{kJ} \cdot \mathrm{mol}^{-1}\end{array}$} & \multicolumn{8}{|c|}{ Power law model parameters } & \multirow[t]{2}{*}{ Extra $T$} \\
\hline & & & $\begin{array}{c}J_{0} \\
\left(\mathrm{GPa}^{-1}\right)\end{array}$ & $k$ & $\begin{array}{c}a_{1 \lambda} \\
\left(10^{-5}\right)\end{array}$ & $\begin{array}{c}a_{2 \lambda} \\
\left(10^{-3}\right)\end{array}$ & $\lambda_{60}$ & $\begin{array}{c}\log \tau_{0} \\
(\mathrm{~s})\end{array}$ & $\begin{array}{c}W \\
\mathrm{~kJ} \cdot \mathrm{mol}^{-1}\end{array}$ & $\begin{array}{c}\text { RMS error } \\
(\%)\end{array}$ & \\
\hline Licania alba & 480 & 311 & 0.044 & 0.12 & 4.94 & -0.14 & 1.04 & 15.5 & 322 & 0.09 & $55-65-70$ \\
\hline Oxandra asbeckii 1 & 763 & 391 & 0.058 & 0.16 & 1.57 & 1.89 & 1.07 & 14.6 & 288 & 0.11 & 45 \\
\hline Oxandra asbeckii 2 & 487 & 237 & 0.055 & 0.18 & 5.15 & 1.05 & 1.08 & 12.1 & 228 & 0.07 & 70 \\
\hline Dicorynia guyanensis & 628 & 355 & 0.053 & 0.07 & 0.48 & 0.97 & 1.03 & 23.0 & 367 & 0.07 & \\
\hline Lecythis persistens 1 & 561 & 254 & 0.064 & 0.13 & 3.80 & 0.85 & 1.06 & 14.8 & 275 & 0.07 & $55-70$ \\
\hline Lecythis persistens 2 & 623 & 419 & 0.062 & 0.13 & 6.97 & -0.51 & 1.05 & 16.3 & 385 & 0.14 & \\
\hline Lecythis persistens 3 & 501 & 315 & 0.065 & 0.15 & 7.08 & -0.18 & 1.06 & 13.7 & 335 & 0.21 & \\
\hline Lecythis persistens 4 & 513 & 327 & 0.051 & 0.11 & 7.32 & -0.70 & 1.04 & 17.1 & 305 & 0.11 & \\
\hline Virola michelii 1 & 558 & 265 & 0.113 & 0.05 & 2.92 & 0.65 & 1.05 & 25.2 & 315 & 0.05 & \\
\hline Virola michelii 2 & 486 & 69 & 0.099 & 0.07 & 4.66 & 1.79 & 1.10 & 17.6 & 62 & 0.06 & \\
\hline
\end{tabular}

$W_{0}$ : activation energy deduced from horizontal shifts of raw experimental data. $W_{J-T_{+}}$: activation energy deduced from horizontal shifts of experimental data corrected by softening factor $\lambda$. Parameters of the power law [Eq. (6)]: $J_{0}$ : initial compliance, $k$ : power parameter, $a_{1 \lambda}: a_{2 \lambda}$ : parameters of the polynomial temperature dependency of the softening factor $\lambda$ [Eq. (7)], $\lambda_{60}$ : softening factor for $60^{\circ} \mathrm{C}$ expressing the amplitude of the temperature effect on the compliance, $W$ : activation energy, RMS error: root mean square error between modelled and measured compliance values. Extra $T$ : temperatures tested above the standard temperatures. 


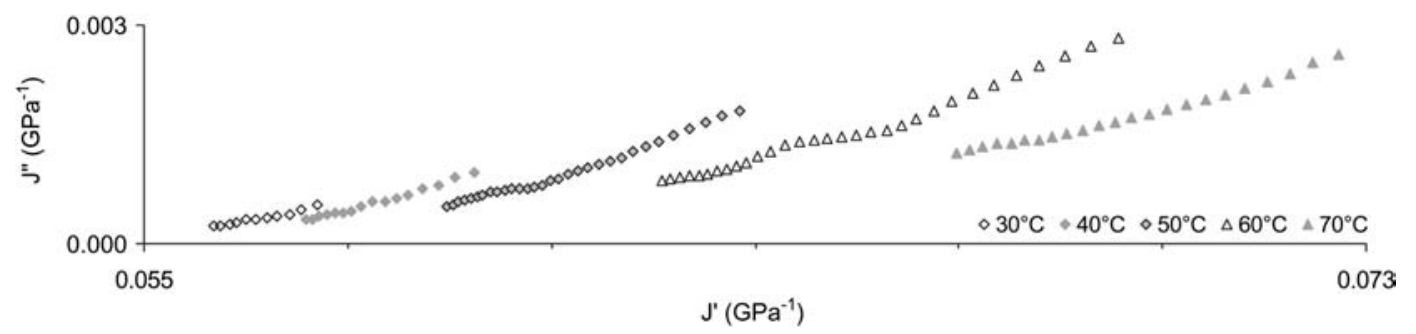

Figure 6 Smoothed experimental data for the Oxandra asbeckii 2 specimen plotted in the approximated complex plane (ACP) for different creep temperatures $J^{\prime}$ and $J^{\prime \prime}$ : Alfrey's approximations of storage and loss compliance, respectively [Eqs. (1) and (2)].

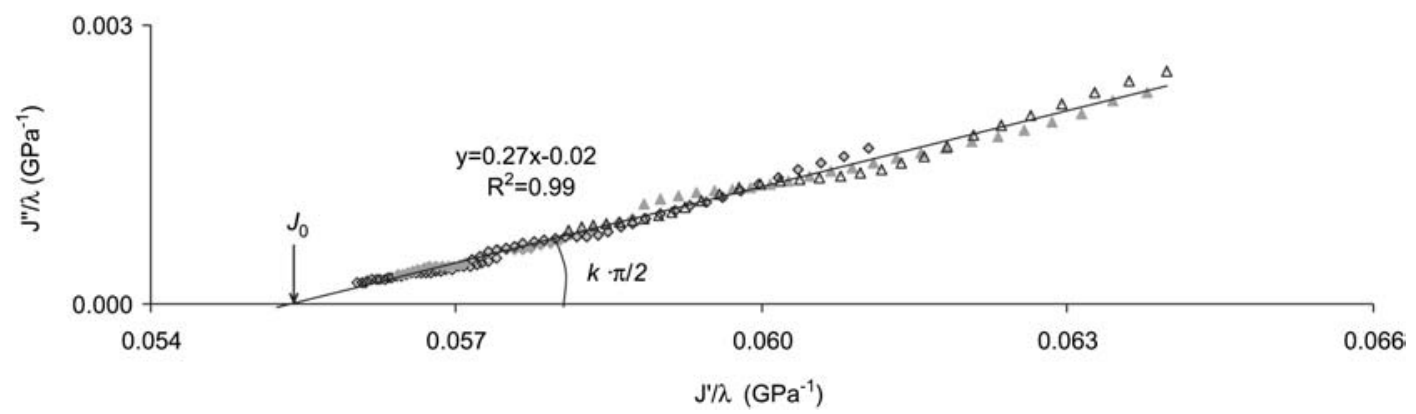

Figure 7 ACP of Figure 6 corrected by the softening factor $\lambda . J_{0}$ : initial compliance, $k$ : power exponent. $J^{\prime}$ and $J^{\prime \prime}$ : Alfrey's approximations of storage and loss compliance, respectively [Eqs. (1) and (2)].

that could explain the observed discontinuities between individual creep curves.

Based on the assumption of the $J$ - $T$ effect, a two-step procedure was applied on the experimental data. First, the effect of temperature on the compliance was removed by performing a homothetic transformation of creep curves in the ACP. Multiplicative factors $\lambda_{(T)}$ were adjusted to obtain a continuous curve, taking a test performed at $30^{\circ} \mathrm{C}$ as reference. Resulting curve in the transformed ACP (i.e., $J^{\prime \prime} / \lambda$ vs. $J^{\prime} / \lambda$ ) was approximated by a 2nd degree polynomial to allow for variations in the slope; however, a linear approximation was sufficient (Figure 7). $\lambda_{(T)}$ factors used for the correction were plotted with respect to temperature increase (Figure 8). An increase of temperature resulted in values of $\lambda_{(T)}>1$, indicating some type of material softening. The relationship between both parameters in Figure 8 was essentially linear, however, 2 nd degree polynomial was necessary for some specimens and was finally used for all the specimens.

Once the condition of continuity between curves in the ACP was satisfied, we applied the time-temperature equivalency. Data corrected for the $J-T$ effect $(J / \lambda)$ were used to construct the master curve. Plot of log time shifts vs. $1 / T$ again shows agreement with Arrhenius law to model thermal activation of green wood after correction (Figure 5). However, the slope of the regression line, proportional to the activation energy (denoted $W_{J-T+}$ in Table 2) was very different: omitting the effect of temperature on the compliance resulted in larger apparent time-temperature shift factors imparting different kinetics of the creep response. Similar observation was made on polymethylmethacrylat (PMMA) by McCrum and Morris (1964) who stated temperature dependency of limiting modulus, analogical to our $J_{0}$ temperature dependency. Moreover, accounting for the $J-T$ effect yields perfectly smooth master curve (Figure 9). Thus, the assumption of temperature dependent compliance was included in the rheological model.

\section{Identification of the rheological model}

Based on the graphical representation of experimental data in the transformed ACP, close to a straight line, a "parabolic Maxwell" model (Huet 1988) was used to describe green wood creep. The behaviour of such an element is governed by a power law that can be written as:

$J(t ; T)=\lambda(T) \cdot J_{0}\left[1+\left(\frac{t}{\tau(T)}\right)^{\mathrm{k}}\right]$

where $J(t ; T)$ is the creep compliance, $\lambda$ the multiplicative factor accounting for thermal softening of the compliance,

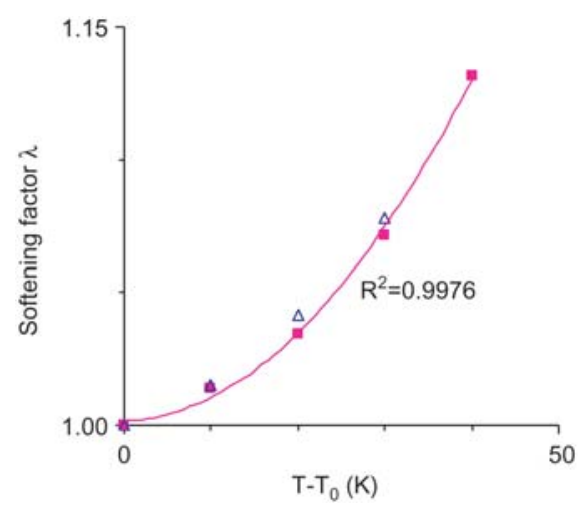

Figure 8 Temperature dependency of the softening factor $\lambda$ (Oxandra asbeckii 2 specimen). The legend is the same as for Figure 5. 


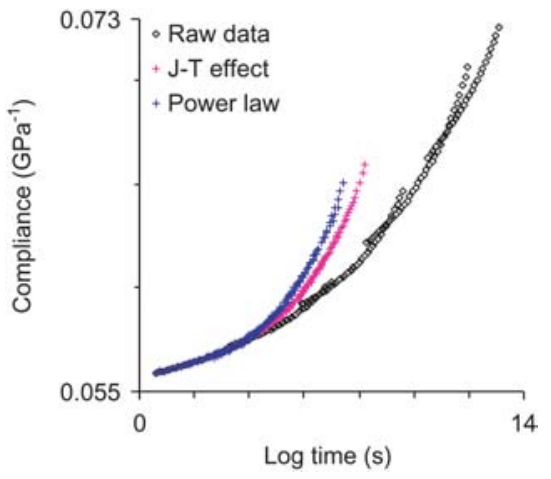

Figure 9 Master curves for the Oxandra asbeckii 2 specimen corresponding to different assumptions. Raw data: experimental data from Figure 4 shifted along the log time axis. J-T: experimental data corrected by softening factor $\lambda$. Power law: modelled values based on Eqs. (6-8) accounting for the time-temperature dependency and softening factor $\lambda$.

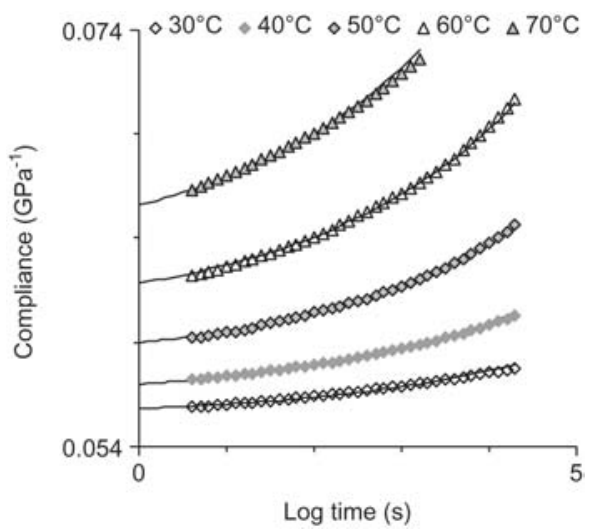

Figure 10 Agreement between experimental data for the Oxandra asbeckii 2 specimen (markers) and the power law model (lines): power law $J-T$ effect and Arrhenius law [Eqs. (6-8)].

$J_{0}$ the initial compliance, $\tau$ the doubling time, and $k$ the kinetic parameter (Figure 7).

We used the same $k$ for all the creep tests of a given specimen. This implies that the straight lines corresponding to individual tests in the ACP have the same slope. It can be seen from Figure 7 that this assumption is rather well satisfied. On the contrary, parameters $\lambda$ and $\tau$ are dependent on the temperature. Softening factor dependency on temperature is empirically modelled by a polynomial of the 2 nd degree (Figure 8 ) and evolution of $\tau$ is governed by the same Arrhenius law as Eq. (4):

$\lambda(T)=1+a_{1 \lambda} \cdot\left(T-T_{0}\right)+a_{2 \lambda} \cdot\left(T-T_{0}\right)^{2}$

$\ln \tau(T)=\ln \tau_{0}+\frac{W}{R} \cdot\left(\frac{1}{T}-\frac{1}{T_{0}}\right)$

where $T$ is temperature, $T_{0}$ the reference temperature, and $\tau_{0}$ doubling time at $T_{0}$ with $a_{T, T_{0}}=\tau / \tau_{0}$. The model parameters [Eqs. (6-8)] are directly identified on raw creep tests curves (Figure 10) and are presented in Table 2.

\section{Model parameters comparison}

For some specimens, the time-temperature shift factor for creep test performed at $70^{\circ} \mathrm{C}$ was not consistent with the Arrhenius law. This was ascribed to the vicinity of glass transition temperature for lignin (Salmén 1984) and corresponding creep curves were not used for further analysis. Also, for specimens used during preliminary tests at many temperatures (see column "Extra $T$ " in Table 2 for details), only those carried out at "standard" temperatures $\left(30^{\circ} \mathrm{C}-40^{\circ} \mathrm{C}-50^{\circ} \mathrm{C}-60^{\circ} \mathrm{C}\right)$ were used to enable comparison between specimens. However, note that including these data yields a negligible effect on the tuned parameter values for the rheological model. This confirmed the robustness of the proposed model.

Table 2 summarises the rheological parameters obtained by the different methods developed previously. $W_{o}$ is the activation energy derived from time shift factors used for the construction of the master curve from raw experimental data (only $t-T$ effect). Second value of activation energy, $W_{J-T+}$, is obtained from the data corrected by the softening factor $\lambda$. The third set of data represents parameters of the rheological model governed by a power law with polynomial temperature dependency of the softening factor $\lambda$ and Arrhenius law accounting for the time-temperature equivalency [Eqs. (6-8)]. Softening factor, $\lambda_{60}$ gives the magnitude of the temperature effect on the compliance at $60^{\circ} \mathrm{C}$ for comparison. Finally, the relevance of the model is assessed through the root mean square error (RMS error) between modelled and measured compliance values.

The activation energy describes the magnitude of timestretching effect of the temperature; higher values correspond to stronger temperature effect. From the comparison between $W_{o}$ and $W_{J-T+}$ presented in Table 2, it can be seen that including the $J-T$ effect has reduced the apparent time-temperature effect. Consequently, corresponding master curves have different kinetics, as illustrated in Figure 9. Except for one specimen (Virola michelii 2), values of activation energy are similar for all the specimens, the average being $545 \mathrm{~kJ} \mathrm{~mol}^{-1}$ for $W_{o}$ and $319 \mathrm{~kJ} \mathrm{~mol}^{-1}$ for $W$. Compared to bibliographic data deduced from the $\tan \delta$ peak dependency on frequency, not affected by the presumed temperature effect on the compliance $\left(\tan \delta=J^{\prime \prime} / J^{\prime}\right)$, the assumption of thermal softening seems to yield more consistent values of the activation energy (395 kJ mol-1 in Salmén 1984; $339 \mathrm{~kJ} \mathrm{~mol}^{-1}$ in Kelley et al. 1987).

For the $V$. michelii 2 specimen, the raw value of the activation energy is consistent with others $\left(W_{0}=486 \mathrm{~kJ}\right.$ $\mathrm{mol}^{-1}$ ) if we do not take into consideration the transgression of the time-temperature equivalency, i.e., discontinuity between creep curves observed in the ACP. However, once the time-temperature equivalency is applied based on the $J-T$ effect, very poor thermal activation is observed $\left(W_{J-T+}=66 \mathrm{~kJ} \mathrm{~mol}^{-1}\right)$. Conversely, temperature effect on the compliance is larger than in other specimens $\left(\lambda_{60}=1.1\right.$ against the average of 1.05).

The rheological model showed very good agreement between modelled and experimental values for the whole specimens, as illustrated in Figure 10 (see RMS in Table 2 ), in spite of contrasted values of $J_{0}$ resulting from the structural diversity of the studied samples. Values of the activation energy are very close to $W_{J-T_{+}}$and are rather consistent between specimens (i.e., standard deviation as low as $15 \%$ ). This is quite interesting as it gives some 
idea on the physical meaning of this factor: it should not be affected much by structural parameters but rather by the chemistry. On the other hand, the variability of the kinetic parameter $k$ and doubling times $\tau_{0}$, likely related to the structural diversity, was significant between specimens (around 30\%). This opens perspectives on future work relying on the understanding of the physical meaning of the model parameters.

\section{Conclusion}

The time-temperature equivalency can be applied on green wood only if an additional temperature effect is considered concerning the compliance, similar to the case of entropic elasticity in rubber. The effect could be seen as some type of material softening with increasing temperature. This means that temperature affects not only the kinetics but also the intensity of viscoelastic processes. The rheological model governed by a power law accounting for this effect has shown its relevance. The delayed behaviour of the tropical species investigated is proof of this. The link between the model parameters and the structural features of wood material is still not clear. The entropic elasticity and the way to model it in wood must be investigated further.

\section{References}

Alfrey, T. Mechanical Behaviour of High Polymers. Interscience, New York, 1948.

Bardet, S. (2001) Comportement thermoviscoélastique transverse du bois humide. PhD Thesis, Université Montpellier 2 (In French). 226 pp.

Ferry, J.D. Viscoelastic Properties of Polymers. John Willey, New York, 1980.

Fournier, M., Baillères, H., Chanson, B. (1994) Tree biomechanics: growth, cumulative prestresses, and reorientations. Biomimetics 2:229-251.
Genevaux, J.-M. (1989) Le fluage à température linéairement croissante: caractérisation des sources de viscoélasticité anisotrope du bois. PhD Thesis, Institut National Polytechnique de Lorraine (in French). 198 pp.

Gril, J., Fournier, M. (1993) Contraintes d'élaboration du bois dans l'arbre: un modèle multicouche viscoélastique, Actes du 11 e congrès français de Mécanique, 6-10 septembre 1993, Lille - Villeneuve d'Ascq, Association Universitaire de mécanique/Groupe de concertation de mécanique. pp. 165-168.

Gril, J., Thibaut, B., Berrada, E., Martin, G. (1993) Recouvrance hygrothermique du bois vert. I. Influence de la température. Cas du jujubier (Ziziphys lotus (L) Lam). Ann. Sci. Forestières 50:57-70.

Huet, C. (1988) Some aspects of the termo-hygro-viscoelastic behaviour of wood. In: Colloque Scientifique Européen, 8 et 9 juin 1988, Bordeaux. Ed. Bois, G.S.R.D. Bordeau. pp. 104-116.

Hunt, D.G., Darlington, M.W. (1978) Accurate measurement of creep of nylon-6,6 at constant temperature and humidity. Polymer 19:977-983.

Kelley, S.S., Rials, T.G., Glasser, W.G. (1987) Relaxation behaviour of the amorphous components of wood. J. Mater. Sci. 22:617-624.

Le Govic, C., Felix, B., Hadj Hamou, A., Rouger, F., Huet, C. (1987) Mise en évidence d'une équivalence temps-température et modélisation du fluage du bois, Actes du $2 \mathrm{e}$ colloque Sciences et Industries du Bois, Nancy, 22-24 avril 1987 - tome 1. A.R.BO.LOR, Nancy. pp. 349-356.

McCrum, N.G., Morris, E.L. (1964) On the measurement of the activation energies for creep and stress relaxation. Proc. R. Soc. Lond. Ser. A, Math. Phys. Sci. 281:258-273.

McCrum, N.G., Read, B.E., Williams, G. (1967) Anelastic and Dielectric Effects in Polymeric Solids. Wiley, London. 617 pp.

Placet, V., Passard, J., Perré, P. (2007) Viscoelastic properties of green wood across the grain measured by harmonic tests in the range $0-95^{\circ} \mathrm{C}$ : hardwood vs. softwood and normal wood vs. reaction wood. Holzforschung 61:548-557.

Salmén, L. (1984) Viscoelastic properties of in situ lignin under water-saturated conditions. J. Mater. Sci. 19:3090-3096.

Wilson, B.F., Archer, R.R. (1979) Tree design: some biological solutions to mechanical problems. Bioscience 9:293-298.

Received July 28, 2008. Accepted January 8, 2009.

Previously published online February 18, 2009. 